\title{
Effect of contact material on vibration-induced insulin aggregation
}

\author{
V. Feingold ${ }^{1}$, A. B. Jenkins ${ }^{2}$ and E.W. Kraegen ${ }^{2}$ \\ ${ }^{1}$ Department of Mechanical Engineering, University of Sydney and Telectronics Bioengineering Research Centre, Lane Cove, \\ and ${ }^{2}$ Garvan Institute of Medical Research, St. Vincent's Hospital, Darlinghurst, NSW. Australia
}

\begin{abstract}
Summary. The tendency of insulin to form insoluble aggregates is a major obstacle to the development of implantable insulin infusion systems for treatment of insulin-deficient diabetic patients. A test system was developed to examine the kinetics of insulin aggregation under controlled conditions of temperature, vibration and contact material in an effort to provide design criteria for minimising aggregation. The contact materials tested were all potentially suitable for pump reservoirs on engineering criteria and included metals (stainless steel, titanium and a titanium alloy) and various plastics (polypropylene, polytetrafluoroethylene, polyvinylchloride, polyamide, cellulose butyrate and silicone elastomer). The rate of insulin aggregation was markedly affected by the nature of the contact material. Hydrophilic materials, particularly polyamide and cellulose butyrate ( $2 \%$ of total insulin aggregated after $96 \mathrm{~h}$ vibration), appeared more compatible with insulin stability than did hydrophobic ones, such as polypropylene (16\% aggregation) and polyvinylchloride (37\% aggregation). A specially formulated 'pump' insulin preparation, stabilised by addition of polyethylenepolypropyleneglycol, was signifi-
\end{abstract}

cantly superior (three to five times more stable) to a regular neutral insulin formulation under most, but not all, conditions. Standard clinical syringes (polypropylene) performed poorly with both insulin formulations but especially with the neutral regular insulin (100\% aggregation after $96 \mathrm{~h}$ vibration). In addition to physical aggregates, significant amounts $(5 \%-30 \%)$ of the insulin remaining in solution were no longer detectable by immuno- or receptorassay in all materials tested. Appropriate combinations of insulin formulations and materials can minimise insulin aggregation and denaturation, but since the mechanisms involved are as yet poorly understood, realistic testing of proposed reservoir components and insulin formulations must be a prerequisite in insulin infusion pump planning and design. These testing procedures should be designed to test for denaturation in solution as well as for precipitation of insulin.

Key words: Insulin, administration and dosage, therapeutic use, insulin infusion devices.
Substantial advances have been made in the treatment of diabetes, using artificial insulin delivery systems and implantable devices, which are now being used in man $[1,2]$. These devices are intended for long-term treatment and thus require reservoirs with the capacity to store insulin from months to years.

A major problem hindering the application of implantable insulin delivery devices is the aggregation of insulin at body temperature in the reservoir and associated tubing. Lougheed and Albisser reported luminal obstructions in implantable pumps [3] and other reports of insulin aggregation have been published [4, 5]. In addition, there are recent reports on the circulation and deposition of amyloid proteins following continuous insulin infusion treatment in man [6] and dogs [7]. A further report suggests that this does not occur in dogs when insulin aggregates are excluded by an on-line filter [8].

Many factors have been implicated as causes of insulin aggregation, including purity, metal ions, temperature, processing, motion and ionic strength [4]. How- ever, as neither the nature of the products of insulin polymerisation nor the mechanism(s) of their formation are clear at present, it would seem important to investigate insulin aggregation in an environment relevant to implantable delivery systems. The environmental factors most relevant to such applications are body temperature, vibration and contact with the reservoir's material.

To date no quantitative work has been reported analysing the influence of materials on insulin aggregation under well controlled environmental conditions. Tests in vivo have not considered the effect of various materials, while tests in vitro have used materials such as glass vials which are very unlikely to be used in implantable delivery systems or have used mixtures of materials so that assessment of individual materials is complicated [9]. We have therefore examined insulin aggregation under controlled conditions of temperature, vibration and material using both a regular neutral insulin preparation and a specially formulated 'pump' insulin preparation in an attempt to provide design criteria for mini- 
mising insulin aggregation in implantable insulin infusion devices. In view of a recent report on the formation of soluble denatured insulin derivatives in an in vitro test system [10], a separate series of studies was performed to assess the quantitative significance of this process in our test system and to assess the effect, if any, of contact material.

\section{Materials and methods}

\section{Insulin preparations}

Two types of highly purified insulin solution of $100 \mathrm{U} / \mathrm{ml}$ were used: (a) neutral regular insulin (phosphate buffered porcine, Nordisk, Gentofte, Denmark, batch numbers 10043, 10053, 10062). This phosphate buffered insulin was found to be the least susceptible to aggregation of a number of clinical preparations tested in a recycling peristaltic pumping system [11]. (b) Specially formulated insulin for pumps with an additive of polyethylenepolypropylene glycol (porcine HOE 21 PS, Hoechst, Frankfurt, FRG, batch number 010481/1; Dr. U. Grau, Hoechst, personal communication). In later studies examining formation of soluble denatured insulin (Fig. 4A), for which HOE 21 PS was unavailable, studies were performed using human HOE 21 PH insulin (batch number ChB 48, Hoechst).

\section{Reservoir materials}

A range of materials potentially suitable on engineering criteria for implantable pump reservoirs was tested: polypropylene (PPH, Gehr Kunststoffwerk, Mannheim, FRG); polyamide-6 (TK6, TKG Ensinger, Nufreingen, FRG); polyethylene (HDPE Gehr Kunststoffwerk, Mannheim, FRG); cellulose butyrate (235 MS Eastman Chemical Products, Kingsport, Tennessee, USA); polyvinyl chloride (Rigid, Gehr, Kunststoffwerk, Mannheim, FRG); polytetrafluoroethylene (BS4271, Grade A1, Pumpus Fluorplast, Newcastle, UK); stainless steel (316, Sandvik, Sydney, Australia); titanium (IMI 130, IMI, Birmingham, UK); silicon elastomer (Silastic Type A, Dow Corning, Midland, Michigan, USA); titanium alloy (IMI 318, IMI).

An independent laboratory (Analchem Consultants, Lilyfield, NSW, Australia) analysed the plastics to verify the supplier's specifications. The plastics were also tested for leachable material and conformed to US Pharmacopeia standards [12].

Screw top vials with an internal volume of $2.5 \mathrm{ml}$ were machined from the various materials. The surface finish in all vials was identical, with a surface texture of $0.8 \mu \mathrm{m}$ (Rugotest-1, Etalon, Rolle, Switzerland). Prior to use (and re-use) vials were cleaned in an ultrasonic bath with freon followed by distilled $\mathrm{H}_{2} \mathrm{O}(\mathrm{x} 4), \mathrm{HCl} / 95 \%$ ethanol, $\mathrm{pH} 2$ (x2), $0.1 \mathrm{~mol} / 1 \mathrm{NaOH}(\mathrm{x} 1)$ and distilled $\mathrm{H}_{2} \mathrm{O}(\mathrm{x} 6)$ rinses. This procedure allowed repeated use of the vials without affecting their behaviour in the test system.

Of additional interest was the performance of polypropylene syringes in our test system in view of the increasing use of external syringe based insulin infusion pumps for diabetic therapy. Two types of commercially available syringes were tested: a $2 \mathrm{ml}$ polypropylene syringe (Terumo, Melbourne, Australia) and a $5 \mathrm{ml}$ polypropylene syringe (Pharmoplast, Sydney, Australia). Both types were silicone lubricated. Thirty syringes of each type were tested as supplied with a further six of each type tested after being subjected to the washing procedure described above.

\section{Vibration testing}

Capped vials containing $2 \mathrm{ml}$ of insulin preparation and sealed externally with Nescofilm (Nippon Shoji Kaisha, Osaka, Japan) were fixed rigidly onto a specially constructed vibration table within a temperature controlled enclosure $\left(37.0 \pm 0.5^{\circ} \mathrm{C}\right)$. The vials were vibrated vertically at $50 \mathrm{~Hz}$ with a peak acceleration of $2 \mathrm{~g}$ for specified times. These parameters are within the range of those to which an implanted infu- sion device could be subjected intermittently. Syringes were part filled leaving an air space, capped with polypropylene luer caps (Astra Pharmaceuticals, Sydney, Australia) and clamped rigidly to the vibration table.

\section{Insulin aggregation and denaturation}

Aggregates formed were collected by centrifugation, washed by resus pension in distilled $\mathrm{H}_{2} \mathrm{O}(\mathrm{x} 2)$, dissolved in $\mathrm{NaOH}(0.1 \mathrm{~mol} / \mathrm{l})$ and assayed for protein using a modification of the method of Lowry et al. [13], using porcine insulin as a standard. Aggregated insulin is expressed as a percentage of total insulin originally in solution $( \pm \mathrm{SEM})$. Insulin content of the fresh formulations was determined by protein assay of trichloroacetic acid precipitates [13] and was 3.9 and $3.7 \mathrm{mg} / \mathrm{ml}$ for neutral regular and specially formulated preparations respectively. In one series of experiments, insulin denaturation following vibration was assessed by measurement of insulin immunoreactivity and receptor binding activity remaining in solution. The specially formulated insulin used in this series of experiments contained human insulin. Insulin immunoreactivity was measured in a double-antibody radioimmunoassay [14] against a human insulin standard using an anti-insulin antiserum which reacts identically with porcine and human insulin. Insulin receptor binding activity was measured in a radioreceptor assay against a human insulin standard, using microsomal membranes prepared from full term human placentas as a source of insulin receptor [15]. Both the radioimmunoassay and radioreceptor assay used ${ }^{125} \mathrm{I}$-human insulin as tracer. Denaturation of insulin as determined by radioimmunoassay and radioreceptor assay is expressed as a percent age of insulin activity lost from solution $( \pm$ SEM) compared with measured insulin activity in the fresh formulations.

In kinetic experiments, repeated sampling for assay of protein was not practical and changes in turbidity were used to monitor aggregation. Turbidity was measured as optical density at $360 \mathrm{~nm}$. This wavelength was chosen to optimise light scattering by insulin aggregates while minimising absorbance in fresh insulin preparations. Turbidity was calibrated against amount of aggregated protein, using a series of samples vibrated for different periods in vials of various materials. Separate calibrations were necessary for the two insulin preparations used.

\section{Electron microscopy}

Insulin aggregates were collected by centrifugation, washed by resuspension in distilled $\mathrm{H}_{2} \mathrm{O}$, pelleted and lyophylised. Gold-coated preparations were examined at various magnifications under a scanning electron microscope (Model JSM 35C, Jeol, Tokyo, Japan).

\section{Statistical methods}

The significance of the effects of contact material on the different measures of insulin aggregation and denaturation was determined by analysis of variance (ANOVA). In experiments where aggregation only was measured, one way ANOVA was used followed, where appropriate, by Tukey's test for comparisons between individual materials. In experiments where the four different parameters of insulin loss from solution were compared, a three factor design was used (main effects: material, analytical method and replication with repeated measures on replication). The strength of correlations between the various parameters was determined as Pearson's product moment correlation coefficient (r). Numerical values are expressed as mean \pm SEM.

\section{Results}

\section{Electron microscopy and solubility}

All insulins subjected to vibration at $37^{\circ} \mathrm{C}$ in our system exhibited some degree of aggregation. A scanning electron microscope was used to study the aggregates de- 


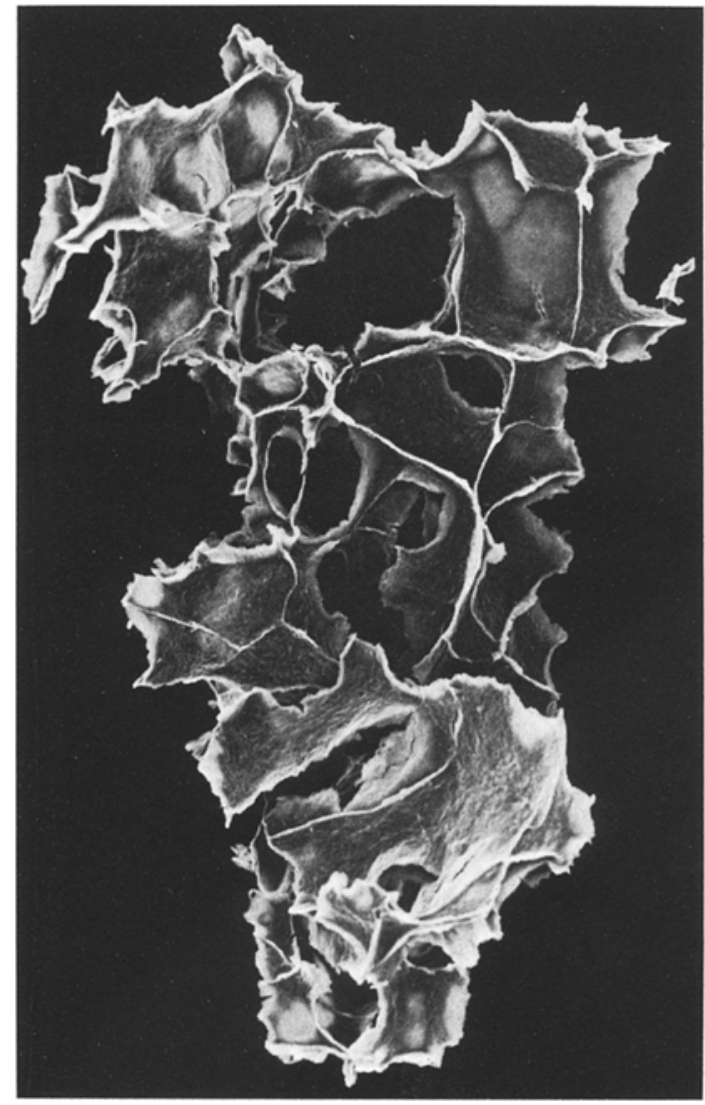

Fig. 1. Scanning electron micrograph of lyophilised neutral regular insulin aggregate from polypropylene syringe $\left(96 \mathrm{~h}\right.$ vibration, $37^{\circ} \mathrm{C}$ ) $(\times 120)$

rived from neutral regular insulin and revealed aggregates of irregular shapes (Fig.1). These aggregates resembled those found by Schade et al. in reservoirs implanted in dogs [5]. The aggregates were insoluble at $\mathrm{pH}$ 3 but soluble at $\mathrm{pH} 10$.

\section{Calibration of turbidity versus insulin aggregation}

The relationships between turbidity (optical density at $360 \mathrm{~nm}$ ) and percentage insulin aggregation (protein assay) for the two insulin preparations are shown in Figure 2. Light scattering is strongly dependent on the size and shape of the particles responsible and it is likely that the different relationships observed with the two preparations are due to differences in the particulate structures produced. It appears from Figure 2 that the combination of specially formulated insulin and cellulose butyrate vials conform closely to the relationship obtained for neutral regular insulin.

\section{Kinetics}

The kinetics of insulin aggregation in various materials in both neutral regular and specially formulated insulin preparations show the initial lag phase and subsequent exponential phase, characteristic of an autocatalytic mechanism (Fig. 3). It is apparent that the rate of aggregation of both insulin preparations is markedly affected

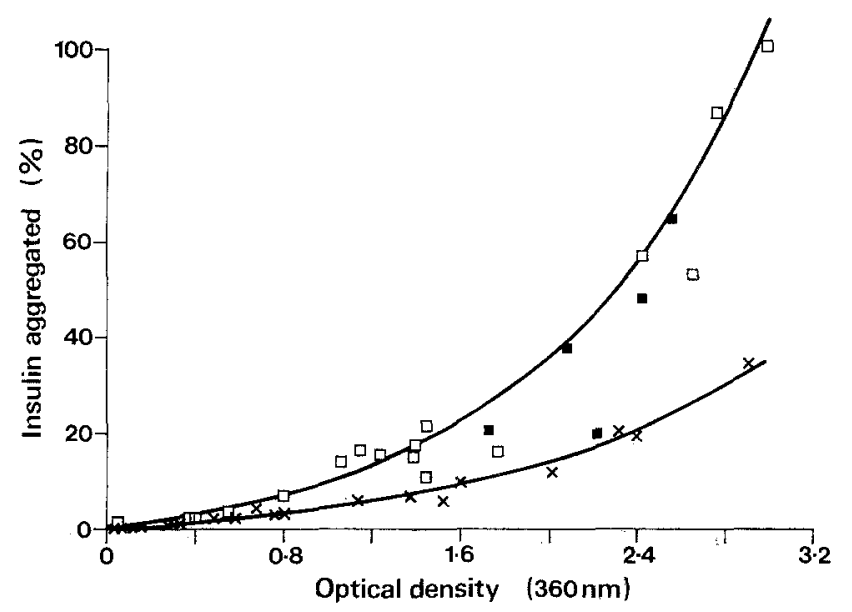

Fig. 2. Calibration of percentage insulin aggregation versus optical density at $360 \mathrm{~nm}$. $\square$ Neutral regular insulin, $x$ specially formulated


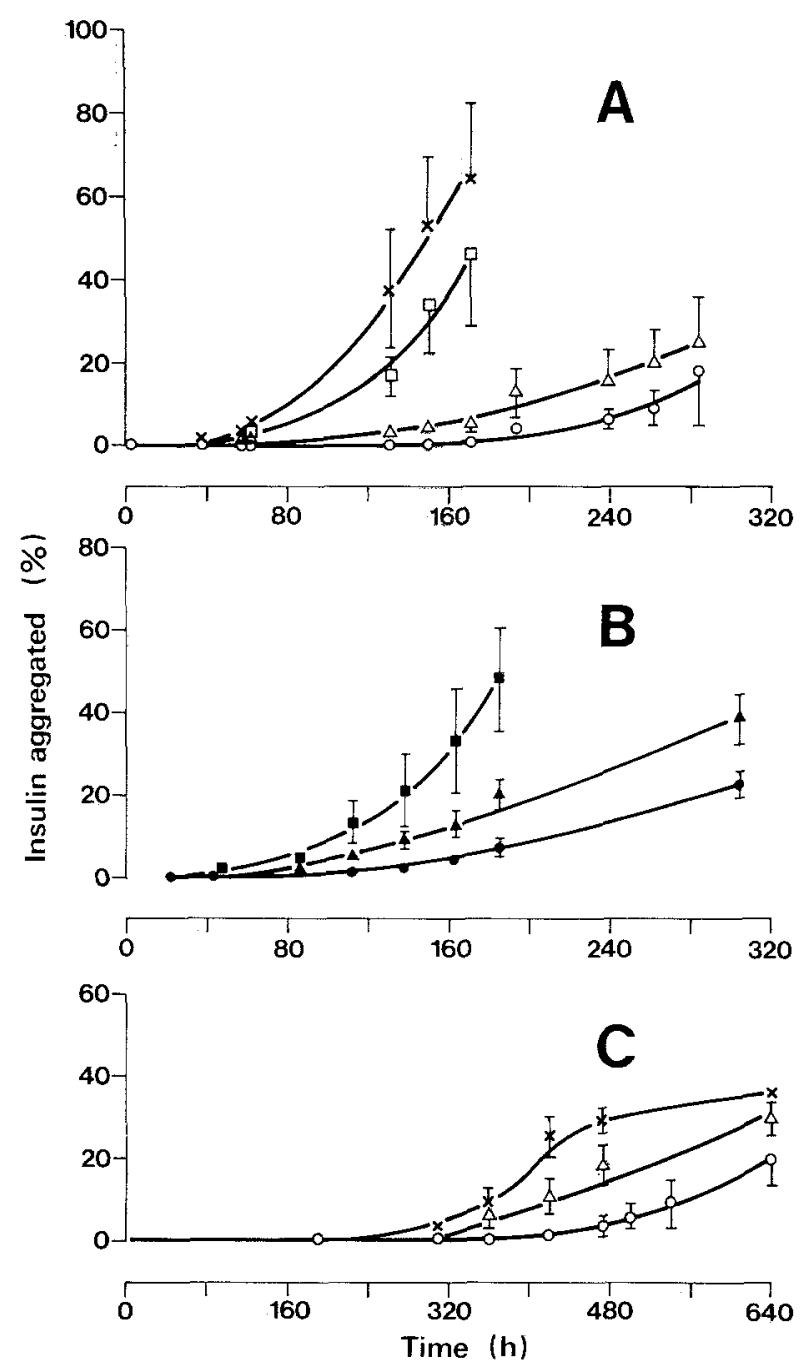

Fig.3. Time course of aggregation of neutral regular insulin (A, B) and specially formulated insulin (C) in polypropylene ( $\mathrm{x}$ ), polyethylene $(\square)$, titanium $(\triangle)$, polyamide $(o)$, silicone elastomer $(\mathbf{Q})$, titanium alloy $(\Delta)$ and stainless steel $(\bullet)$ containers. Bars represent mean $\pm S E M$ 
Table 1. Aggregation of neutral regular insulin and $\mathrm{pH}$ after $96 \mathrm{~h}$ of vibration $\left(2 \mathrm{~g}, 50 \mathrm{~Hz}, 37^{\circ} \mathrm{C}\right)$

\begin{tabular}{lccl}
\hline Material & $\begin{array}{l}\text { Number } \\
\text { of vials }\end{array}$ & $\begin{array}{l}\text { Aggregation } \\
(\%)\end{array}$ & $\mathrm{pH}$ \\
\hline Polyamide & 11 & $1.7 \pm 0.2^{\mathrm{a}}$ & $7.19 \pm 0.04$ \\
Cellulose butyrate & 12 & $2.3 \pm 0.7^{\mathrm{a}}$ & $7.22 \pm 0.02$ \\
Titanium & 6 & $2.9 \pm 0.7^{\mathrm{a}}$ & $7.23 \pm 0.01$ \\
Silicone elastomer & 6 & $6.5 \pm 2.2^{\mathrm{a}, \mathrm{c}}$ & $7.35 \pm 0.01$ \\
Polypropylene & 12 & $16.3 \pm 2.4^{\mathrm{b}}$ & $7.35 \pm 0.01$ \\
Polytetrafluoroethylene & 7 & $12.3 \pm 5.4^{\mathrm{b}, \mathrm{c}}$ & $7.30 \pm 0.01$ \\
Polyvinylchloride & 6 & $36.6 \pm 2.8^{\mathrm{d}}$ & $7.32 \pm 0.02$ \\
Polypropylene (syringe) & 42 & $100^{\mathrm{c}} \dagger$ & $7.29 \pm 0.01$ \\
\hline
\end{tabular}

Results expressed as mean \pm SEM. Mean values are significantly different $(p<0.05)$ from other materials not carrying the same letter superscript e.g. Polytetrafluoroethylene was different from all other materials except polypropylene and silicone elastomer.

$\dagger$ Approximate figure only. Optical density exceeded the upper limit of reading in all cases

Table 2. Aggregation of specially formulated insulin and $\mathrm{pH}$ after $360 \mathrm{~h}$ of vibration $\left(2 \mathrm{~g}, 50 \mathrm{~Hz}, 37^{\circ} \mathrm{C}\right)$

\begin{tabular}{llll}
\hline Material & $\begin{array}{l}\text { Number } \\
\text { of vials }\end{array}$ & $\begin{array}{l}\text { Aggregation } \\
(\%)\end{array}$ & $\mathrm{pH}$ \\
\hline Polyamide & 5 & $0.6 \pm 0.2^{\mathrm{a}}$ & $7.30 \pm 0.02$ \\
Polypropylene & 4 & $2.2 \pm 0.6^{\mathrm{a}}$ & $7.33 \pm 0.05$ \\
Polytetrafluoroethylene & 5 & $4.7 \pm 2.3^{\mathrm{acc}}$ & $7.33 \pm 0.03$ \\
Titanium & 5 & $5.5 \pm 1.5^{\mathrm{a}, \mathrm{c}}$ & $7.30 \pm 0.05$ \\
Polypropylene (syringe) & 5 & $14.2 \pm 6.0^{\mathrm{b} . \mathrm{c}}$ & $7.31 \pm 0.02$ \\
Cellulose butyrate & 5 & $47.4 \pm 7.0^{\mathrm{d}}$ & $7.35 \pm 0.02$ \\
\hline
\end{tabular}

Results expressed as mean \pm SEM.

Mean values are significantly different $(p<0.05)$ from other materials not carrying the same letter superscript

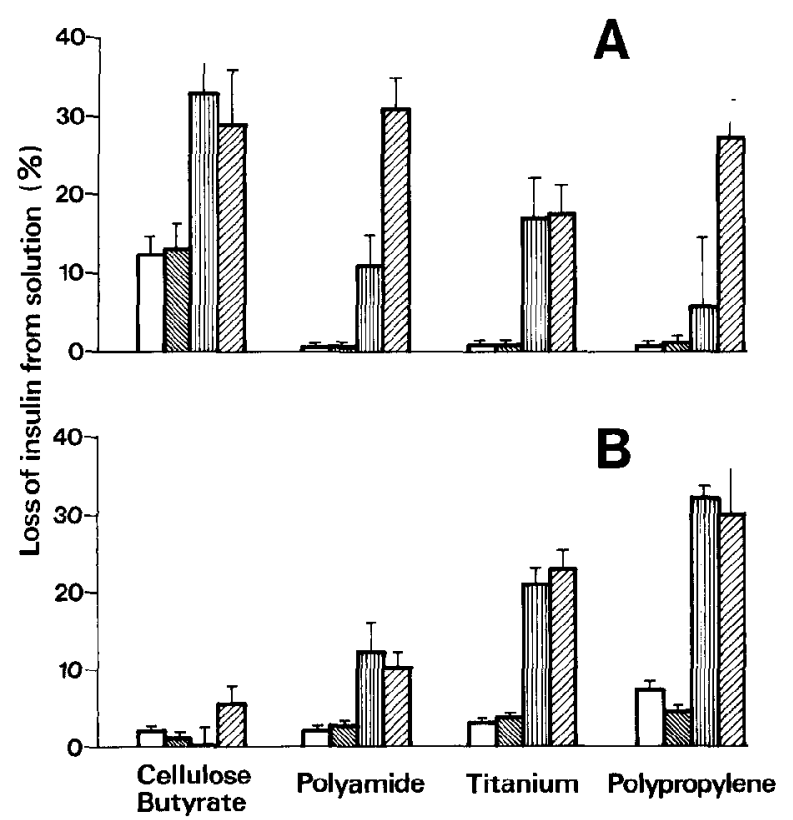

Fig.4. Effect of contact on aggregation and denaturation of specially formulated insulin after $320 \mathrm{~h}$ vibration (A) and neutral regular insulin after $96 \mathrm{~h}$ vibration (B) as determined by four methods: turbidity $(\square)$, protein precipitated ( $\mathbb{}$ ), radioimmunoassay (III), and radioreceptor assay $(\mathbb{Z})$. Mean \pm SEM by the nature of the contact material. Also apparent is the relative resistance of specially formulated insulin to aggregation compared to neutral regular insulin. Taking the time required to reach 5\% aggregation as an empirical measure of insulin stability, specially formulated insulin is three to five times more stable than neutral regular insulin under our test conditions.

On the basis of these results, suitable vibration times were chosen for fixed time tests to maximise differences between materials. Ninety-six and $360 \mathrm{~h}$ were chosen for neutral regular insulin and specially formulated insulin respectively.

\section{Formation of insoluble aggregates}

The percentage aggregation of neutral regular insulin after $96 \mathrm{~h}$ and specially formulated insulin after $360 \mathrm{~h}$ in various materials is shown in Tables 1 and 2, respectively. In addition, since small changes in $\mathrm{pH}$ have been suggested to contribute to insulin aggregation, the $\mathrm{pH}$ of the suspension after vibration is also tabulated. Starting $\mathrm{pH}$ was 7.30 (neutral regular) and 7.35 (specially formulated). There was no significant correlation between $\mathrm{pH}$ and degree of aggregation for either preparation.

There was a highly significant effect of contact material on insulin aggregation with both formulations $(\mathrm{F}=39.6, p<0.001$, neutral regular; $\mathrm{F}=34.8, p<0.001$, specially formulated). Individual comparisons of material effects on neutral regular insulin identified four groups of materials with minimal overlap between groups. Polyamide, cellulose butyrate and titanium all produced $<3 \%$ aggregation over $96 \mathrm{~h}$. Silicone elastomer, polypropylene and polytetrafluoroethylene comprised a second group showing moderate $(7 \%-16 \%)$ aggregation, while polyvinylchloride $(37 \%)$ and polypropylene syringes $(100 \%)$ showed significantly more aggregation than all other materials. The behaviour of the two types of syringes was indistinguishable and was not affected by the washing procedure; the results of all groups were pooled. It should be noted that the three materials showing least aggregation constitute a group of relatively hydrophilic materials. With the specially formulated insulin, all of the materials tested performed better, or no worse, with respect to aggregation over $360 \mathrm{~h}$ compared with their behaviour with neutral regular insulin over $96 \mathrm{~h}$, with the exception of cellulose butyrate. Individual comparisons of material effects on specially formulated insulin identified three groups of materials. Polyamide and polypropylene showed least aggregation $(1 \%-2 \%)$, while polytetrafluoroethylene $(5 \%)$, titanium $(6 \%)$ and polypropylene syringes $(14 \%)$ constituted an intermediate group and cellulose butyrate $(47 \%)$ showed significantly more aggregation than all other materials. There was no obvious relationship between aggregation and the hydrophilic properties of the materials with specially formulated insulin.

\section{Formation of soluble denatured insulin}

A further series of studies was performed to determine whether soluble forms of denatured insulin were pro- 
duced in our test system and to assess the effects of contact material on this process, if present. The specially formulated porcine insulin was not available for this series of studies and was replaced by the human insulin special formulation. The effects of vibration in various materials on insulin denaturation, as measured by loss of immunoreactivity or receptor binding activity, are shown in Fig. 4A (specially formulated insulin) and Fig. 4B (neutral regular insulin). The materials used were chosen to be representative of the range of effects on aggregation seen with both formulations. The two measures of insulin aggregation (turbidity and protein precipitated) determined on the same samples are shown for comparison. There was a marked effect of contact material on the measures of insulin denaturation (radioimmunoassay and radioreceptor assay) with neutral regular insulin and little or no effect with specially formulated insulin. There was good agreement between the measures of neutral regular insulin aggregation in this vibration run (Fig. 4 B) with those seen in the same materials in the previous run (Table 1 ). However there was less aggregation of specially formulated insulin in all materials (Fig. 4 A) compared to the previous run (Table 2), although the materials did rank in the same order with respect to degree of aggregation produced.

There was a marked effect of assay method on the estimate of total insulin loss from solution with both insulin formulations $(\mathrm{F}=35.9, p<0.001$, neutral regular; $\mathrm{F}=31.5, p<0.001$, specially formulated). This is clearly due to a marked discrepancy between the measures of physical aggregation and receptor or antibody binding activity (Fig. 4). Thus there appears to be significant formation of soluble denatured derivatives of insulin with both formulations. Furthermore, there was a significant statistical interaction between contact material and assay method with both formulations suggesting that contact material discriminately affects formation of aggregates and soluble denatured forms of insulin $(F=6.48$, $p<0.001$, neutral regular; $\mathrm{F}=2.10, p<0.05$, specially formulated).

There were significant positive correlations between the two measures of insulin denaturation (radioreceptor and radioimmunoassay) with both formulations ( $r=0.70, p<0.01$, neutral regular; $r=0.46, p<0.05$, specially formulated) although there was a suggestion that the two parameters may be affected differently under some conditions (see polyamide and polypropylene, Fig. 4A). There were also significant positive correlations between turbidity (aggregation) and immunological potency (radioimmunoassay) for both formulations ( $r=0.72, p<0.01$, neutral regular; $r=0.53, p<0.01$, specially formulated) but not between turbidity and receptor binding activity ( $r=0.40$, neutral regular; $r=0.23$, specially formulated).

\section{Discussion}

The results obtained demonstrate that vibration of two types of insulin formulations under our conditions leads to formation of both physical aggregates of insulin and soluble denatured forms. The test conditions used are within the range of environmental conditions to which an implanted insulin infusion system could be exposed intermittently. Continuous exposure to these conditions would therefore be expected to accelerate rather than alter the nature of the aggregation and denaturation processes. In support of this with regard to aggregation is the similarity under scanning electron microscopy of the aggregates obtained here with those obtained from an implanted infusion device [5]. In addition, the solubility of the aggregates at acid and alkaline $\mathrm{pH}$ is similar to those produced in vivo [5] and is consistent with insulin fibril formation [16]. The kinetics of aggregate formation were consistent with an autocatalytic mechanism, a feature of fibril formation [17]. We have previously shown that seeding a solution with preformed insulin aggregates markedly accelerates the rate of aggregate formation in a recycling peristaltic pumping system [11], a finding consistent with the present kinetic data. If conditions which completely prevent insulin aggregation in implanted systems are not attainable, effective cleaning procedures for refillable reservoirs in situ may be important in infusion system design.

Turbidity at $360 \mathrm{~nm}$ provided an accurate and reproducible estimate of insulin aggregation provided the correct standardisation for each formulation was performed. The nature of the contact material has marked effects on insulin aggregation in both formulations. With neutral regular insulin, hydrophilic materials produced least aggregation. With the specially formulated insulin, there was no apparent relationship between aggregation and the hydrophilic properties of the materials. The specially formulated insulin performed markedly better than the neutral regular insulin with all materials except cellulose butyrate. The aggregation seen in cellulose butyrate with specially formulated insulin was in marked contrast to that of the other hydrophilic materials tested with this formulation (i.e. polyamide and titanium). The reasons for this discordant behaviour are not clear but it could, for example, be due to absorption of the stabiliser from solution by cellulose butyrate, although other mechanisms are possible.

It was noted that the standard clinical polyproplene syringes performed poorly with respect to insulin aggregation with both insulin formulations, especially the neutral regular insulin (Table 1). These types of syringes do not appear to cause significant clinical problems when used with external insulin infusion devices for periods of 1-3 days. However, if applications over longer periods of time are envisaged, it may be desirable to look for alternative materials for syringe construction.

There was good agreement between the amounts of regular insulin aggregation seen in the various materials in the two separate experiments (Table 1, Fig. 4B). However, the human insulin special formulation (Fig. 4A) showed substantially less aggregation than the porcine insulin special formulation (Table 2) under the same conditions. It is not clear whether this is an effect due to 
different insulins or to other differences that may exist between the two formulations.

The production of substantial amounts $(5 \%-30 \%)$ of soluble denatured insulin derivatives under our conditions was an unexpected finding. The formation of similar material has been reported in another in vitro test system [10], but we are not aware of any reports of its occurrence during clinical or experimental insulin pump use. If a similar process does occur during insulin pump therapy, it may have several implications. Firstly, it would imply a reduction in potency of the infused insulin with a consequent need to increase infusion rates to achieve adequate metabolic control. Secondly, it may have implications related to the antigenic and other biological properties of this presumably inactive insulin. The nature of the contact material appeared to affect the production of soluble denatured insulin in parallel with its effect on aggregation with neutral regular insulin. In fact, we would rank the performance of materials with neutral regular insulin in the same order for each of the four tests applied for aggregation or denaturation (Fig.4B). This was not the case with specially formulated insulin where the effect of material on denaturation was reduced or absent (Fig. 4A).

The mechanisms responsible for insulin aggregation and denaturation are not clear, nor is the relationship between the two processes. That this relationship may not be direct is supported by the significant discriminatory effect of contact material on the two processes. This is illustrated in Figure 4A where specially formulated insulin showed minimal aggregation in polyamide and titanium, but substantial loss of immuno- and receptor-binding activity in solution in these materials.

In summary, this study highlights the dual nature of the problem of insulin stability in infusion systems. The mechanisms responsible for aggregation and denaturation are poorly understood and empirical testing under realistic conditions provides the only guide for material and formulation selection for infusion system design. Our data demonstrate that aggregation can be minimised by judicious selection of materials and insulin formulations, but also indicates that unpredictable deleterious interactions between these components can occur. Furthermore, the absence of significant insulin aggregation does not necessarily imply that an insulin formulation retains full activity.

Note added in proof: It has been brought to our attention that the data presented above does not exclude the possibility that the discrepancy between the protein assay and the immuno- and receptor-assays (Fig. 4) could be explained by absorption of insulin to the surface of the containers. This was tested and found not to be the case with the neutral regular insulin. Total recovery of protein after vibration was determined as the sum of aggregated protein and protein remaining in solution measured in a Coomassie Blue binding assay (Bio-Rad Laboratories, Richmond, California) against a porcine insulin standard. Recovery of protein was not affected by material (cellulose butyrate: $104 \pm 6 \%$; polyamide $105 \pm 3 \%$; titanium: $100 \pm 3 \%$; polypropylene: $95 \pm 3 \% ; \mathrm{F}=1.42 ; \mathrm{NS}$ ) and was $100.7 \pm 2.0 \%$ overall. Thus, there was no detectable loss of insulin by absorption surfaces.

Acknowledgements. We are grateful to Telectronics Pty. Limited for their generous support in this project. We also wish to thank Dr.
Y.W. Mai of the University of Sydney for helpful discussions and Dr. C.E. Nockolst of the University of Sydney for providing electron microscopy facilities. We wish to acknowledge the gifts of HOE-21 PS and HOE-21 PH insulin from Dr. M.Zoltobrocki, Hoechst, and the comments of Drs. M.Zoltobrocki and U.Grau on aspects of this study. This work was supported in part by a grant from the National Health and Medical Research Council of Australia.

\section{References}

1. Schade DS, Eaton RP, Edwards WS, Doberneck RC, Spencer WJ, Carlson GA, Bair RE, Love JT, Urenda RS, Gaona JI (1982) A remotely programmable insulin delivery system. JAMA 247: 1848-1853

2. Rupp WM, Barbosa JJ, Blackshear PJ, McCarthy HB, Rohde TD, Goldenberg FJ, Rublein TC, Dorman FD, Buchwald H (1982) The use of an implantable insulin pump in the treatment of type II diabetes. New Engl J Med 307: 265-270

3. Lougheed WD, Albisser AM (1980) Insulin delivery and the artificial beta cell: luminal obstructions in capillary conduits. Int J Art Org 3: 50-56

4. Lougheed WD, Woulfe-Flanagan H, Clement JR, Albisser AM (1980) Insulin aggregation in artificial delivery systems. Diabetologia 19: 1-9

5. Schade DS, Eaton RP, Delongo J, Saland LC, Ladman AJ, Carlson GA (1982) Electron microscopy of insulin precipitates. Diabetes Care 5: 25-30

6. Brownlee M, Cerami A, Li JJ, Vassara H, Martin TR, McAdam KPWJ (1984) Association of insulin pump therapy with raised serum amyloid $A$ in type I diabetes mellitus. Lancet 1: 411-413

7. Albisser AM, McAdam KPWJ, Perlman K, Carson S, Bakoric A, Williamson JR (1983) Unanticipated amyloidosis in dogs infused with insulin. Diabetes 32: 1092-1101

8. Mauer SM, Buchwald H, Groppoli TJ, Rohde TD, Wigness BD, Rupp WM, Steffes MW (1983) Failure to find amyloidosis in dogs treated with long-term intravenous insulin delivered by a totally implantable pump. Diabetologia $25: 448-450$

9. Lougheed WD, Albisser AM, Martindale HM, Chow JC, Clement JR (1983) Physical stability of insulin formulations. Diabetes 32: 424-432

10. Brange J, Havelund S (1983) Insulin pumps and insulin quality requirements and problems. Acta Med Scand Suppl 671: 135-138

11. James DE, Jenkins AB, Kraegen EW, Chisholm DJ (1983) Insulin precipitation in artificial infusion devices. Diabetologia 21: 554-557

12. The United States Pharmacopeia (1980) Twentieth Revision, p 953

13. Peterson GL (1977) A simplification of the protein assay method of Lowry et al. which is more generally applicable. Anal Biochem $83: 364-356$

14. Morgan CR, Lazarow A (1963) Immunoassay of insulin: two antibody system: plasma levels of normal, subdiabetic, diabetic rats. Diabetes 12: 115-126

15. Marshall RN, Underwood LE, Vorna SJ, Foushee DB, Van Wyk JJ (1974) Characterisation of the insulin and somatomedin-C receptors in human placental cell membranes. J Clin Endocrinol Metab 39: 283-292

16. Waugh DF (1948) Regeneration of insulin from insulin fibrils by the action of alkali. J Am Chem Soc 70: 1850-1857

17. Waugh DF (1950) Assay of insulin in vitro by fibril elongation and precipitation. J Biol Chem 185: 85-95

Received: 27 September 1983

and in revised form: 18 June 1984

Dr. E.W. Kraegen

Garvan Institute of Medical Research

St. Vincent's Hospital

Darlinghurst, NSW 2010

Australia 